\title{
A Comparison between the Same-Ethnicity and Cross-Ethnicity Friendship Quality of Early Adults in Karachi
}

\author{
Dr. Zeenat Ismail \\ Professor - Department of Social Sciences \& Liberal Arts \\ Institute of Business Administration - Karachi
}

\begin{abstract}
This research compares the friendship quality of young adults between same ethnicity and cross ethnicity in Karachi. The participants were 200 in total and were divided into 100 majority ethnicity group and 100 minor ethnicity group. They answered the McGill Friendship Questionnaire-Responder's (MFQ-RA). The results showed that there was no significant difference in the same ethnicity friendship quality between ethnic majority and minority groups. However the comparison of same ethnicity and cross ethnicity friendship quality by gender shows a significant difference in both positive feelings and satisfaction. Females got significantly higher friendship satisfaction in cross ethnicity but no significant difference in positive feeling.
\end{abstract}

Key Terms: Same ethnicity, Friendship quality, Cross-Ethnicity, Early Adults.

\section{Friendship Quality}

\section{DEFINITIONS}

The meaning of friendship could differ from person to person and from time to time for the individual because of the ever changing dimension of friendship quality. 'The general definition for friendship quality is the satisfaction each partner receives from a relationship'. (Aboud \& Mendelson, 1996). Researches have defined this quality into six dimensions of social and emotional resources. 'These dimensions include both positive and negative aspects of friendship.' (Berndt \& Perry, 1986). In this study the two dimensions for friendship quality examined as per the MC GRAW HILL questionnaire are friendship satisfaction and positive feelings for a friend.

\section{Adults}

'A young adult is generally a person in the age range of 20 to 39 (or 40), whereas an adolescent is a person aging from 13 to 19' (Wikipedia). For the purpose of this research we have taken early/young adults who fall in the age group $18-25$. This is the age group which is termed as emerging adulthood by Arnett after his research on Adults when the most common response he got from 18 - 29 years old was 'I feel in between adult and adolescence'. (Arnett, 2000)

\section{Ethnicity}

The three terms race, culture and ethnicity are often interchangeable. The characteristics of ethnicity include language, nationality and culture. In Greek concepts, the term ethnos refer to people of a particular tribe or nation and thus ethnicity is affiliation to a particular group which in normal terms is said as culture. However, this distinction in important in researches from a psychology view point because as much as being part of a cultural group can give ethnic identity, the interaction between other ethnic groups can influence culture. There are several variables for culture differences in the psychological phenomena of ethnic groups and one such variable is language. For the purpose of our study we have taken Lingo-ethnicity in which the 
majority ethnicity consists of Majority language speaking people in Karachi i.e. Urdu and Punjabi and Minority Ethnicity consists of Minority languages such as Sindhi, Guajarati, Hyderabadi, Shina, Memoni and others.

\section{INTRODUCTION}

Friendship, just like any other relationship is very personal in nature and is formed on the common grounds of care and concern for each other. The idea of care could be of varying nature but there must be some intimacy or love in friendship which allows them to experience emotions such as joy on account of their friends success and disappointment/sadness on accounts of failure. Aristotle said "A friend, then, is one who wishes and does good (or apparently good) things to a friend, for the friend's sake, wishes the friend to exist and live, for his own sake, spends time with his friend, makes the same choices as his friend and finds the same things pleasant and painful as his friend." It is possible that friends are very different from each other in their interests, values and histories but they will still be playing vital roles in each other's lives.

Friendship plays a significant role in ones' happiness and well-being as it is a close association between two people who have mutual respect, hobbies, compassion and concern for each other. The many perks of friendships include advancement in career, knowing ourselves better and shape our thoughts and behaviors. The experience of friendship can prove to be an extremely powerful one in influencing ones moral development according to a research done on the links between the two (Rachel, 2001). There are several studies that have also been conducted to see how middle adult friendship varies from adolescence. These studies confirm that friendship is a very important part of forming ones personality and developing an identity. However, not all adolescence friendships continue to adulthood which is another aspect in friendship quality which confirms the presence of situational control over long lasting friendships. (Hallinan and Rawlins,1993) Friendships with more diverse people also allow acceptance to different ideas and values and develop our thinking skills which are seen as predictors to cognitive development. Moreover friendships also shape in context to the parenting style in adolescence. Very authoritative parents will not take a back seat even in early adulthood and will continue to influence his interpersonal relationships. So it is likely that their prejudices about a particular group of people enters the attitudes of their child and becomes an underlying factor in choosing friends. (Raboteg-Saric and Sakic, 2013) In general, all researches done on friendships have revolved around the question of how the social and psychological adjustments are positively affected by high quality friendships. However, it is important to see how one defines and assesses this friendship quality.

One of the earliest researches of friendship quality was on preadolescence friendships where high quality friendships were characterized by intimacy and self-disclosure. (Sullivan, 1953). However, the features of friendship quality are prone to differ with age. Children go by the old proverb, 'a friend in need is a friend indeed.' For them helping and sharing are the two features which are the hall mark of friendship quality whereas for emerging adults the sharing of personal feelings and loyalty demonstrate friendship quality. Friendship quality also plays a role in determining the self-esteem. This is especially true for young adults and also correlates to friendships between opposite genders. (Arroyo and Segrin, 2011) In our research we measure friendship quality by the positive feeling and satisfaction. There are consistent findings with the direct effect of friendship quality self-esteem, social stressors and social adjustments. (Harper \& Stevens, 1999). However there have been studies which show that the friendship quality did not result in enhancing self-esteem (Berndt \& Keefe , 1996). One possible explanation for this is the negative aspects of friendship quality in contrast to the positive aspects. The negative aspects include controlling, over possessive behavior and 
jealousy. Also the magnitude of friends' influence is also dependent on the quality of friendship. Ethnicity is a very important factor here because it associates with diverse friendships which result in social adjustments to stoichiometric status, peer victimization and peer support. Researches have led to the conclusion that cross ethnic friendship quality results in a decrease to the toil social adjustment takes for ethnic minority groups. (Kawabata and Crick, 2011) . The friendship quality among diverse friendships is also linked to the social Anxiety disorder. Research has found impaired friendship quality leads to anxiety and this can become an economic burden if the mental health of the people is affected. (Rodebaugh, Fernandez and Levinson, 2012).

Despite several researches in the understanding of friendship quality, majority of the studies have neglected variations in friendship quality within and cross ethnicity. It is possible that people find it hard to deepen their cross-ethnic friendship due to cultural differences but the availability of ethnicities is also a huge factor. There have been studies that show when ethnicities are heterogonous the cross-ethnicity friendships do occur and result in positive outcomes like pro-social behavior.

There have been mixed finding in literature which are exposed to several limitations. Studies have either studied cross-ethnic friendships or same ethnic friendships solely but not in comparison. Hence our research aims to compare the friendship quality of same ethnicity and cross-ethnicity friends in early adults. This will help us in further gaining insight into several psychological attributes like peer acceptance, pro social behavior relating to diversity in friendships.

\section{LITERATURE REVIEW}

Friendship is based on mutual attractiveness where two people are pleased by, prefer or enjoy each other's company. It is practically impossible to be friends with someone and not like the person. It doesn't mean that there won't be any periods of anger, annoyance or even dislike however the overall feeling would be that of fondness. These feelings can be mutual to the two people (B. Annis, 1987). A study investigated how a single intimate friendship can help foster psychological reliance in British adolescents coming from vulnerable socio-economic background. The survey measured resilience, social support and friendship quality through 409 students. A significant positive relation was found between resilience and the perception of friendship which was buttressed by support seeking and coping mechanisms of externalist nature. Among the two genders, boys were found to be more vulnerable to effects of disengaged coping. It was concluded that close friendship serve to be an important protective mechanism for healthy individuals.

(Graber \& Turner, 2015). Romantic relationships and friendships are a result of interpersonal attraction and, according to research, there are three factors that play a vital role in interpersonal attraction. These factors are similarity, propinquity effect, and attractiveness. The fact that we befriend a certain person and not the other is significantly affected by the interplay of these factors. It follows that these factors should be highlighted more than other factors when individuals describe what they look for in their close friends. The relationship between factors, which are proximity, similarity, and attractiveness, and friendship selection is analyzed in the present study where each participant provided data on the qualities they desire in a close friend. Nevertheless, other factors such as supportiveness, honesty, and trust are underscored more. Attractiveness, proximity, and similarity were not stressed upon and most mentioned by the individuals who provided self-reported data. This does not support our claim that these factors should be highlighted more than other factors when individuals describe what they look for in their close friends. (Roberts-Griffin, 2011) 
Researchers from various disciplines have been working since a decade to carry out tests on several hypotheses that seem to indicate a link between attitude of early adults and behavior of the social group. Not all the studies have buttressed this argument however we can still find sufficient data to indicate that close friends do have an influence on the social behaviors of early adults. (Collins \& Laursen, 1999).

The dimensions of friendship have been researched along the lines on childhood and adolescence however only a meager amount of research has taken place with early adulthood. However there is plenty of evidence which shows that friends might have a crucial role to play in life of an adult. However it is unfortunate that not many researchers have explored such relationships or the impact of influences of such friendships. Thus the data available to answer such questions is very limited hindering us to reach on a conclusion. This gap of lack of literature to find out about the effects of friends influence creates serious problems for us because it can lead to misjudgment.

Friendships exist without boundaries thus they can be with a person of any ethnicity.

As per Heaven, a person's values and belief systems have a strong logical link to the group identities he falls in. The ethnic groups to which an individual belong have a significant role to play in shaping up his identity and impact on how the individual evaluates himself. Heaven's study supported this idea by stating that youth of ethnic groups have a greater chance at adhering themselves to the values of the majority group which shapes their value systems accordingly. This lends support to the idea that not only are values effected by attitudes or behaviors but by group identities. However this can be a threat to the minority ethnic group's survival. (Heaven, 1999)

There are several other studies conducted which emphasize upon the relevance of relationship between value systems and ethnic group. It presented the idea that people generally form friendships along the magnitudes that they value. The results indicated that a person distinguishes himself according to his interests and physical similarities when they associate themselves to a dominant group thus a minority in a particular society would not find such opportunities existing.

In another study conducted prevalent to Asian youths it was reported that with same ethnicity friendships higher rate of activities was reported then with cross-ethnicity or cross-race freindships. Even though friendship activities can be one of the indicators to judge friendship intimacy there are several other factors which can influence. For example s had more activities to share with their friends. Classifying on gender, males had higher reported activities then girls which can be a result of less parental controls over males regarding their after school or weekend activities. Finally, culture greatly determines the importance of friends and the magnitude of activities (Kao \& Joyner, 2004).

Another study aimed at finding out the significances of variation in friendship. The aim of this study was to find out the relation between various friendships and marking out the parameters of social adjustment. This relation is not emphasized enough as it should be developmentally. This study also looked at how the preference for a friendship would mitigate the social processes.

Another research done shows the future application and use of this topic in various disciplines. It talked about whether cross ethnicity friends help buffer the feeling of being misunderstood in interethnic interactions.. There were three samples available to study which helped indicate 
that for ethnic minorities with few White friends had to deal with more stress while interacting with interethnic friends. Another study examined the preferences in early adult for cross ethnic friendship. Different dimensions such as identity, discrimination, depression and diversity. The results showed that lower ethnic identity and acceptance had relations with diversity. A positive correlation in discrimination and depression was found however no significant interaction was shown between cross-ethnic friendships and perceived discrimination. (Anne-Marie, 2013)

\section{STATEMENT OF THE PROBLEM}

What is the comparison between the Same-Ethnicity and Cross-Ethnicity Friendship Quality of Early Adults in Karachi?

\section{Sub-Problem}

What are the gender differences in the friendship quality of Same-Ethnicity and Cross-Ethnicity Friendship Quality of Early Adults in Karachi?

\section{Rationale}

With the increasing urbanization in Pakistan and Karachi being the hub of business due to its port there are a variety of ethnic groups found in this city. This leads to inter-ethnic interactions and transmission of cultures through these interactions. The findings from the study will draw a picture of how the same ethnicity and cross ethnicity friendship quality differs amongst adults. This will shed lights to explore the factors that play a role in interethnic friendship quality (socio-economic status, racial prejudice) and help up to promote such friendships to bring cohesion in a society which is divided into numerous ethnicities.

\section{Hypothesis 1:}

\section{HYPOTHESES}

In same ethnicity friendship, early adults from ethnic majority groups have higher friendship quality for frinds than those from ethnic minority groups.

\section{Hypothesis 2:}

In cross ethnicity friendship, early adults from ethnic majority groups have higher friendship quality than those from ethnic minority groups

\section{Hypothesis 3:}

Females have higher friendship quality for a friend in the same ethnic friendship quality than males.

\section{Hypothesis 4:}

Females have higher friendship quality for a friend in the cross ethnicity early adults.friendship than males.

\section{ASSUMPTIONS}

- The census of lingo ethnicity done in 1998 still applies till date.

- The patterns and results found on the study of the sample of adults aged 18-25 applies to all regardless of their education background, socio economic status etc. 


\section{METHODOLOGY}

\section{Description of the Research setting}

Karachi has about 30 different ethnic languages being spoken. As per the 1998 censes the highest frequency is that of Urdu $48.52 \%$, Punjabi $16.05 \%$. The low frequency languages include Sindhi 7.22\%, Balochi 4.34\% and Others 12.44\% ( Brahui, Hindko, Bourshishki, Shina, Siraiki). (Pbs.gov.pk, 2015) A sample of 125 from the high frequency languages and 125 from low frequency languages were collected from a diverse group of students living in Karachi. Of these 125 samples, 100 quality samples were chosen to tabulate the results

\section{The data to be collected}

The tests were applied to the collected data and formed the basis for further derivations.

\section{Research Design Methodology Selection of Sample}

The sample was selected using non-probability convenient sampling. 125 from the majority ethnicity groups and 125 from the minority sampling group were collected of which about 25 had to be rejected due to certain errors.

\section{Variables}

Hypothesis 1: In same ethnicity friendship, early adults from majority groups have higher friendship quality than those from ethnic minority groups.

Independent Variable: Same Ethnicity \& Cross Ethnicity

Dependent Variable: Friendship Quality

Hypothesis 2: In cross ethnicity friendship, early adults from majority groups have higher friendship quality than those from ethnic minority groups

Independent Variable: Same Ethnicity \& Cross Ethnicity

Dependent Variable: Friendship Quality

Hypothesis 3: Females have higher friendship quality for a friend in the same ethnic friendship quality than males.

Independent Variable: Gender

Dependent Variable: Friendship Quality

Hypothesis 4: Females have higher friendship quality for a friend in the cross ethnic friendship than males.

Independent Variable: Gender

Dependent Variable: Friendship Quality

Hypothesis 1: In same ethnicity friendship, early adults from ethnic majority groups have higher friendship quality than those from ethnic minority groups.

Statistical Test used will be T tests and factor analysis.

Hypothesis 2: In cross ethnicity friendship, early adults from majority groups have higher friendship quality than those from ethnic minority groups.

Statistical Test used will be T tests and factor analysis.

Hypothesis 3: Females have higher friendship quality for a friend in the same ethnic friendship quality than males.

Statistical Test used will be T tests and factor analysis. 
Hypothesis 4: Females have higher friendship quality for a friend in the cross ethnic friendship than males.

Statistical Test used will be T tests and factor analysis.

\section{RESULTS}

\section{A Comparison of the Same-Ethnicity and Cross-Ethnicity Friendship Quality between Ethnic Majority and Minority early adults.}

Table 1) A comparison of the same-ethnicity friendship quality between ethnic majority and minority early adults.

Group Statistics

\begin{tabular}{|cc|c|c|c|c|}
\hline & Ethnicity & $\mathbf{N}$ & Mean & Std. Deviation & $\mathbf{t}(\mathbf{p})$ \\
\hline \multirow{2}{*}{ Positive Feeling } & Majority & 100 & 20.57 & 8.056 & $1.103(.272)$ \\
& Minority & 100 & 19.17 & 7.482 & \\
\hline \multirow{2}{*}{ Friendship Satisfaction } & Majority & 100 & 26.61 & 9.260 & $1.209(.229)$ \\
& Minority & 100 & 24.73 & 9.783 & \\
\hline \multirow{2}{*}{ Overall Frienship } & Majority & 100 & 47.45 & 15.891 & $1.333(.185)$ \\
& Minority & 100 & 43.91 & 16.696 & \\
\hline
\end{tabular}

Table 2) Comparison of cross-ethnicity friendship quality between ethnic majority and minority early adults.

Group Statistics

\begin{tabular}{|c|c|c|c|c|c|}
\hline & Ethnicity & $\mathbf{N}$ & Mean & Std. Deviation & t(p) \\
\hline \multirow{2}{*}{ Positive Feeling } & Majority & 100 & 16.79 & 10.457 & $0.407(.684)$ \\
& Minority & 100 & 17.44 & 9.145 & \\
\hline \multirow{2}{*}{ Friendship Satisfaction } & Majority & 100 & 21.17 & 13.043 & $0.353(.725)$ \\
& Minority & 100 & 21.87 & 10.941 & \\
\hline \multirow{2}{*}{ Overall Frienship } & Majority & 100 & 37.96 & 23.164 & $0.385(.701)$ \\
& Minority & 100 & 39.31 & 19.495 & \\
\hline
\end{tabular}

\section{A Comparison of the Same-Ethnicity and Cross-Ethnicity Friendship Quality by gender.}

Table 3) Comparison of same-ethnicity friendship quality by gender Group Statistics

\begin{tabular}{|cc|c|c|c|c|}
\hline & Gender & $\mathbf{N}$ & Mean & Std. Deviation & t(p) \\
\hline \multirow{2}{*}{ Positive Feeling } & Male & 83 & 17.84 & 8.523 & $3.849(.000178)$ \\
& Female & 67 & 22.39 & 5.898 & \\
\hline \multirow{2}{*}{ Friendship Satisfaction } & Male & 83 & 23.25 & 10.783 & \multirow{2}{*}{$3.770(.000240)$} \\
& Female & 67 & 28.67 & 6.673 & \\
\hline \multirow{2}{*}{ Overall Frienship } & Male & 83 & 41.10 & 18.732 & \multirow{2}{*}{$3.936(.000129)$} \\
& Female & 67 & 51.06 & 12.084 & \\
\hline
\end{tabular}


Table 4) Comparison of cross-ethnicity friendship quality by gender

Group Statistics

\begin{tabular}{|cc|c|c|c|c|}
\hline & Gender & $\mathrm{N}$ & Mean & Std. Deviation & $\mathrm{t}(\mathrm{p})$ \\
\hline Positive Feeling & Male & 83 & 15.18 & 10.015 & $1.117(.266)$ \\
& Female & 67 & 16.84 & 7.619 & \\
\hline Friendship Satisfaction & Male & 83 & 18.77 & 12.177 & $3.219(.002)$ \\
& Female & 67 & 24.93 & 10.942 & \\
\hline \multirow{2}{*}{ Overall Frienship } & Male & 83 & 33.95 & 21.663 & $2.358(0.20)$ \\
& Female & 67 & 41.76 & 18.133 & \\
\hline
\end{tabular}

\section{DISCUSSION OF RESULTS}

The study revealed that the early adults present in Karachi from ethnic majority groups i.e Urdu and Punjabi got higher mean positive feeling and friendship satisfaction for the sameethnicity best friend however the result showed no significant difference. This finding is not consistent with the ethnic differences in friendship quality reported in the literature where the opposite differences were slightly significant (Rodebaugh et al., 2012; Rude \& Herda, 2010). This can be explained through the fact that majority of the sample were students from Karachi of which minority were usually residing in hostels. The majority ethnicity displayed greater positive feelings and satisfaction for same ethnicity friends because they are residents of Karachi, thus having higher recreational activities together. The minority ethnicity spends less quality time with same ethnicity friends thus they scored them low on MFQ-RA.

In cross ethnicity friendship the means of the two friendship dimensions and overall crossethnicity friendship quality for ethnic minority early adults were higher than those for ethnic majority early adults. However as can be seen in Table 2, no significant differences were any significant difference in positive feelings", "friendship satisfaction and overall friendship quality. The difference in the means are backed by previous researches and explained by the fact that minority early adults tend to treasure the cross-ethnicity friendship more than ethnic majority early adults especially since they come from rural areas of Pakistan. However there was no significant difference as Quillian and Campbell (2003) study, suggested that students from ethnic minority groups pursue maintaining a friendship network including several ownrace friends. Also several studies have shown that cross ethnicity friendships tend to be rated lower than same ethnicity friendship which is backed by our data as well (Rude \& Herda, 2010). According to them, cross-race friends are less likely to consider each other as friend.

In terms of the differences in friendship quality between genders, the findings of this study are consistent with previous research (Bae, 2003; Mendelson \& Aboud, 1999, 2012; Rodebaugh et al., 2012; Thomas \& Daubman, 2001). Girls have higher friendship quality than boys for both the same-and cross-ethnicity friendship qualities.

This is because of the difference in perception of men and women. Women tend to be naturally inclined towards being sensitive and attentive to friends. They also rate their friendships using personality characteristics and emphasize greatly upon confidence and trust than men (Bae, 2003; Rodebaugh et al., 2012). Being two year ahead of boys in terms of socio-emotional and intellectual development, girls tend to be more supportive and focus on equality than boys. (De Goede et al., 2009). Females are also more willing to lend their support and share information with their friends which is contrary to their male counterparts. This is fostered by the gender role males have to play in this society which inhibits them to be expressive. (Bae, 2003). The same ethnicity data shows significant differences in both the dimensions of friendships. This helps us to verify that that in this culture boys have to follow a more masculine behavior 
whereas girls are expected to engage in communal behaviors, such as striving for intimacy and connectedness (Zhou, Li, Zhang, \& Zeng, 2012). On the other hand, differences between genders in terms of cross-ethnicity friendship quality were not significant. The factors which might have contributed to this can again be cultural. Females in this culture are not encouraged to have deep and intimate friendships with guys while guys are discouraged to associate with female friends, thus the results had no significant difference.

\section{CONCLUSION}

The results of the study showed a clear picture of how the friendship quality differed in cross ethnicity and same ethnicity and how the two variables of friendship quality (positive feeling and satisfaction) changed. In the same ethnicity friendship quality the majority ethnicity group has more overall friendship quality having both higher satisfaction and positive feelings than those of minority ethnicity groups. In cross ethnicity friendship quality the minority ethnicity group is seen to have higher friendship quality both in terms of positive feeling and satisfaction than the majority ethnicity group. Looking at the gender differences females has higher friendship quality than males in same ethnicity as well as cross ethnicity with both variables of positive feelings and friendship satisfaction higher for men.

There are several limitations which apply to the result of this study. Firstly, the time to carry out the research was limited so the sample of 100 majorities and 100 minorities was not a full representative of all the ethnicities across the country. The ethnicities were not all approachable and hence were done on a lingo-ethnicity basis for which the census of 1998 was taken as it was the latest census available. Also the sample was restrictive to a particular class of people who could read and write in English and fill up the questionnaire. They were all university students and so the public domain selected was also only one i.e. universities. The study assumes that the pattern of results found applies to all the adults that fall in the sample of $18-25$ regardless of their education and socio-economic background. The instrument used measured only two variables of friendship quality and hence cannot be used to see stability over time, racial attitudes and other behaviors.

The delimitations of the study include the differences of gender amongst majority and minority groups in context of cross ethnicity or same ethnicity. The study does not aim to cover any aspects of friendship quality in same gender or across gender. Moreover this was not a longitudinal study so there is no way of determining the stability of the friendships that were taken into account and is not the purpose of the study. The entire adult age group is not studied due to sample size restriction owing to time and hence no aspect of stress related to workplace or any other factor of any public domain is researched.

\section{MANAGERIAL IMPLICATIONS}

Karachi represents a number of ethnicities that our society is divided into and the friendships between those ethnicities can be a representation of the health of inter-ethnic relations at a country level. The results of the research can be used for a variety of practical purposes. With the increasing blend of ethnicity amongst young adults due to reasons of higher education or jobs the cross ethnicity friendships will be a primary part of their interpersonal relationships. And the quality of these relationships can play a part on their success at both career level and academic level. The friendship quality theme of cross ethnicity and same ethnicity arises from adolescents friendships and how they are managed. The Different types of parenting styles can be researched upon in relation to friendship quality within ethnicity and across ethnicity and how they shape in early adulthood. Often people from different ethnicities belong to a different race and social background. For example young adults from rural areas will have a different social status that those living in urban cities like Karachi. The friendship quality can also be a 
measure to explore racial attitude of young adults in befriending or ignoring cross ethnic mates (Aboud, Mendelson and Purdy, 2003). Also the friendship quality that was tested in this research were set on two indices namely positive feeling and satisfaction. This gives ground on further functions of friendship quality to be explored and see how stable they are like emotional security, loyalty and intimacy. The majority ethnicity groups and minority ethnicity groups used in this paper can also be part of inter-group relations within psychology that sociological in nature. The measure of friendship quality can be an index to study prejudices and stereotypes and the social structure and general attitudes of majority groups towards minority groups and vice versa. Our present study focused on friendship quality between same and cross ethnicity that was formed at a public domain i.e. university. From this research we can also derive the contributing factor to friendships that occur beyond school level and encourage student at school to interact amongst cross ethnic peers.

\section{FUTURE RESEARCH SUGGESTIONS}

Future research can actually be targeted towards how parental management shape a young adults approach to cross ethnic friendships. This will result in exploring how to control prejudices and promote interactions between members of society with a different status level. In the long run it will also prove beneficial for the minority ethnicities as the majority ethnicities and well equipped with knowledge, technology and other resources which adds quality to one's life. With a stable friendship aid is likely to flow amongst the two groups of people and result in a more coherent society structure.

While carrying out other researches the place where one is born and brought up can be used as a measure of culture which forms part of one's ethnicity. Language as we have used in our research, although part of ethnicity doesn't really give the ethnic identification to those who don't use it for their majority conversation. Another factor that came across this research was how old the friendships were. Future researches can tune there researches into looking at friendship quality over a particular range of years so that this bias of stability over the years is not present.

\section{References}

Aboud, F. E., Mendelson, M. J., \& Purdy, K. T. (2003). Cross-race peer relations and friendship quality. International Journal of Behavioral Development, 27, 165-173.

Aboud, F., \& Mendelson, M. (1996). Determinants of friendship selection and quality: Developmental perspectives. The company they keep: Friendship in childhood and adolescence (pp. 87-112). New York, NY US: Cambridge University Press.

Anne-Marie Wulff Harcrow, "Cross-ethnic peer preferences in emerging adults" (January 1, 2013). ETD Collection for Fayetteville State University. Paper AAI1524763.

http://digitalcommons.uncfsu.edu/dissertations/AAI1524763

Arnett, J. (2000). Emerging adulthood: A theory of development from the late teens through the twenties. American Psychologist, 55(5), 469-480. http://dx.doi.org/10.1037//0003-066x.55.5.469

Arroyo, Analisa, and Chris Segrin. 'The Relationship Between Self- And Other-Perceptions Of Communication Competence And Friendship Quality'. Communication Studies 62.5 (2011): 547-562. Web.

Bae, Y. A. (2003). Differences in friendship qualities of Korean and American college students. Honors Projects, Illinois Wesleyan University, USA.

B. Annis, D. (1987). The Meaning, Value, and Duties of Friendship. American Philosophical Quarterly, 24(4), 349356.

Berndt, T. J. (2002). Friendship quality and social development. Current Directions in Psychological Science, 11, 710.

Berndt,T.J., \& Keefe,K.(1996). Relations of friendship quality to self-esteem in early adolescence. Journal of early adolescence, 16, $110-129$. 
Berndt, T., \& Perry, T. (1986). Children's perceptions of friendships as supportive relationships. Developmental Psychology, 22, 640-648. doi: 10.1037/0012-1649.22.5.640

Collins, W.A., \& Laursen, B. (Eds.). (1999). Relationships as developmental contexts. Mahwah, NJ: Erlbaum

Crandall, C. S., Schiffhauer, K. L., \& Harvey, R. (1997). Friendship pair similarity as a measure of group value. Croup Dynamics: Theory, Research, and Practice, 1, 133-143.

De Goede, I. H. A., Branje, S. J. T., \& Meeus, W. H. J. (2009). Developmental changes and gender differences in adolescents' perceptions of friendships. Journal of Adolescence, 32, 1105-1123.

http://dx.doi.org/10.1016/j.adolescence.2009.03.002

Graber, R., \& Turner, R. (2015). Best friends and better coping: Facilitating psychological resilience through boys' and girls' closest friendships. British Journal of Psychology, 12(3).

Hallinan, Maureen T., and William K. Rawlins. 'Friendship Matters: Communication, Dialectics, And The Life Course.'. Contemporary Sociology 22.1 (1993): 91. Web.

Hartup, W.W.(1999). Constraints on peer socialization: Let me count the way. Merrill-Palmer Quarterly, 45, 172 183.

Hartup, W.W., \& Stevens, N. (1999). Friendships and adaptation across the life span. Current Directions in Psychological Science, 8, 76-79.

Heaven, P. C. L. (1999). Group identities and human value. The Journal of Social Psychology, 139, 590-595.

Jeffery Simpson, W. Andrew Collins, Sisi Tran, and Katherine Haydon, University of Minnesota; "Attachment and the Experience and Expression of Emotion in Romantic Relationships: A Developmental Perspective," Journal of Personality and Social Psychology, 92, 2.

Kao, G., \& Joyner, K. (2004). Do Race and Ethnicity Matter among Friends? Activities among Interracial, Interethnic, and Intraethnic Adolescent Friends. The Sociological Quarterly, 45(3), 557-573.

Kawabata, Y. (2009). The Significance of Cross-Racial/Ethnic Friendships: Associations with Peer Victimization, Social-Psychological Adjustment, and Classroom Diversity. American Psychologist, 25(4).

Kawabata, Yoshito, and Nicki R. Crick. 'The Significance Of Cross-Racial/Ethnic Friendships: Associations With Peer Victimization, Peer Support, Sociometric Status, And Classroom Diversity.'. Developmental Psychology 47.6 (2011): 1763-1775. Web.

Quyen, L., \& Mohd Zaharim, N. (2012). The Relationship between Friendship Characteristics, Ethnic Identity and Value Systems of Youths from Ethnic Minority Groups in Viet Nam: A Conceptual Framework for Research. International Journal of Humanities And Social Science, 2(23).

Pangle, L.S. (2002). Aristotle and the philosophy of friendship. Cambridge: Cambridge Press

Pbs.gov.pk,. (2015). Population Census / Pakistan Bureau of Statistics. Retrieved 7 December 2015, from http://www.pbs.gov.pk/content/population-census

Phinney, J. S. (2000). Ethnic and racial identity: Ethnic identity. In A. E. Kazdin (Ed.), Encyclopedia of psychology (Vol. 3, pp. 254 -259). New York: Oxford University Press.

Raboteg-Saric, Zora, and Marija Sakic. 'Relations Of Parenting Styles And Friendship Quality To Self-Esteem, Life Satisfaction And Happiness In Adolescents'. Applied Research Quality Life 9.3 (2013): 749-765. Web.

Rachel, E. (2001). The Link Between Friendship and Moral Development. Retrieved from http://www.colby.edu/education/courses/ed318/student_papers/ellis.html

Rodebaugh, Thomas L., Katya C. Fernandez, and Cheri A. Levinson. 'Testing The Effects Of Social Anxiety Disorder On Friendship Quality Across Gender And Ethnicity'.

Roberts-Griffin, C. (2011). What Is a Good Friend: A Qualitative Analysis of Desired Friendship Qualities. Penn Mcnair Research Journal, 3(1).

Rude, J., \& Herda, D. (2010). Best friends forever? Race and the stability of adolescent friendships. Social Forces, 89(2), 585-608. http://dx.doi.org/10.1353/sof.2010.0059

Smith, T. B., \& Silva, L. (2001). Ethnic identity and personal well-being of people of color: A meta-analysis. Journal of Counseling Psychology, 58, 42-60.

Shelton, N., Douglass, S., Garcia, R. L., Yip, T., \& Trail, T. E. (2014). Feeling (Mis) Understood and Intergroup Friendships in Interracial Interactions.Personality and Social Psychology Bulletin, 40(9), 1193-1204. 
Sullivan, H. S. (1953). The interpersonal theory of psychiatry. New York: Norton

Tokuno, K. (1983). Friendship and Transition in Early Adulthood. The Journal Of Genetic Psychology: Research And Theory On Human Development, 143(2).

Zhou, H., Li, Y., Zhang, B., \& Zeng, M. (2012). The relationship between narcissism and friendship qualities in adolescents: Gender as a moderator. Sex Roles, 67, 452-462 http://dx.doi.org/10.1007/s11199-012-0169-8

\section{APPENDIX A: INDEPENDENT STUDY TEST}

\begin{tabular}{|c|c|c|c|c|c|c|c|c|c|}
\hline & \multicolumn{2}{|c|}{$\begin{array}{c}\text { Levene's } \\
\text { Test for } \\
\text { Equality of } \\
\text { Variances }\end{array}$} & \multicolumn{7}{|c|}{ t-test for Equality of Means } \\
\hline & \multirow[t]{2}{*}{$\mathrm{F}$} & \multirow[t]{2}{*}{ Sig. } & \multirow[t]{2}{*}{$\mathrm{t}$} & \multirow[t]{2}{*}{$\mathrm{df}$} & \multirow[t]{2}{*}{$\begin{array}{l}\text { Sig. (2- } \\
\text { tailed) }\end{array}$} & \multirow[t]{2}{*}{$\begin{array}{c}\text { Mean } \\
\text { Difference }\end{array}$} & \multirow[t]{2}{*}{$\begin{array}{l}\text { Std. Error } \\
\text { Difference }\end{array}$} & \multicolumn{2}{|c|}{$\begin{array}{l}95 \% \text { Confidence } \\
\text { Interval of the } \\
\text { Difference }\end{array}$} \\
\hline & & & & & & & & Lower & Upper \\
\hline $\begin{array}{l}\text { Positive } \\
\text { Feeling }\end{array}$ & .439 & .509 & 1.103 & 148 & .272 & 1.400 & 1.270 & -1.109 & 3.909 \\
\hline $\begin{array}{l}\text { Friendship } \\
\text { Satisfaction }\end{array}$ & .350 & .555 & 1.209 & 148 & .229 & 1.880 & 1.555 & -1.194 & 4.954 \\
\hline $\begin{array}{c}\text { Overall } \\
\text { Frienship }\end{array}$ & .048 & .828 & 1.333 & 148 & .185 & 3.547 & 2.662 & -1.713 & 8.806 \\
\hline
\end{tabular}

Table 1) A comparison of the same-ethnicity friendship quality between ethnic majority and minority early adults.

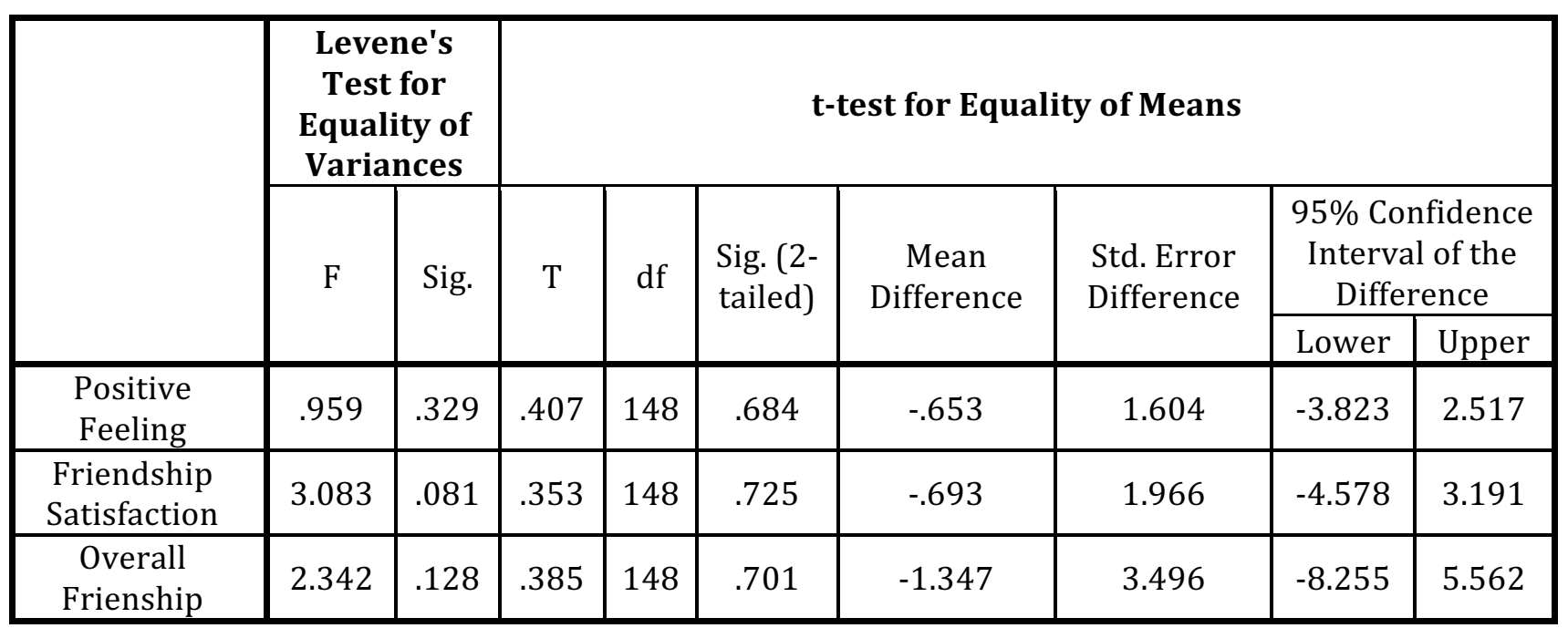

Table 2) Comparison of cross-ethnicity friendship quality between ethnic majority and minority early adults. 


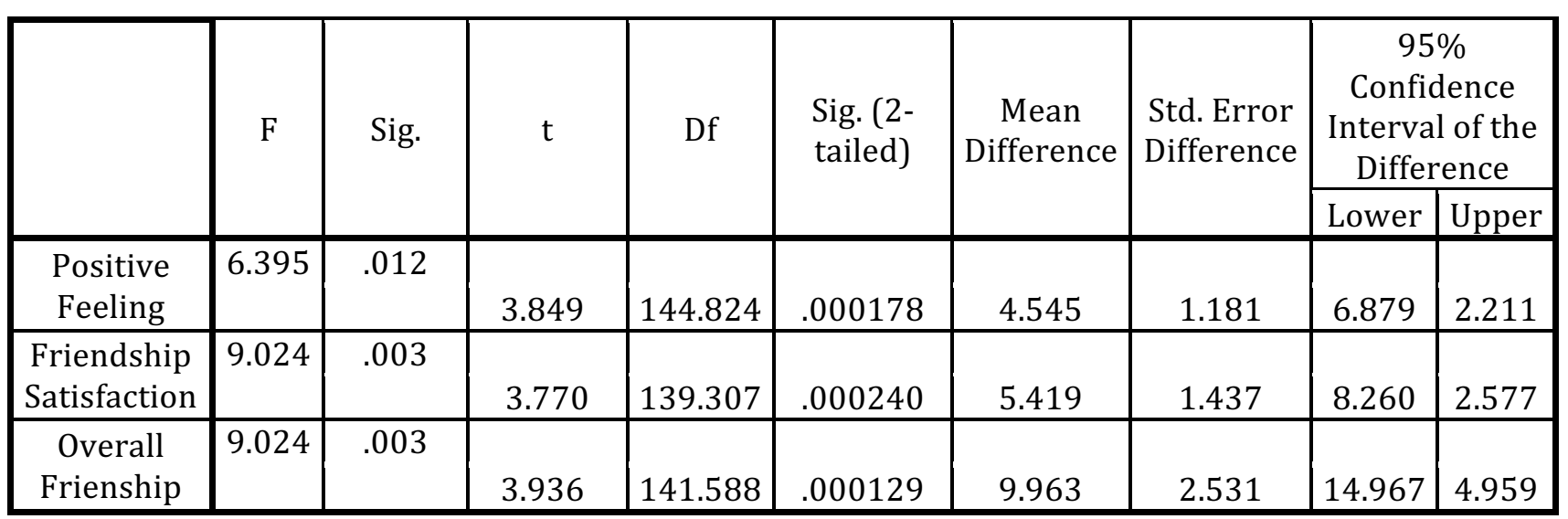

Table 3. Comparison of same-ethnicity friendship quality by gender

\begin{tabular}{|c|c|c|c|c|c|c|c|c|c|}
\hline & \multicolumn{2}{|c|}{$\begin{array}{l}\text { Levene's } \\
\text { Test for } \\
\text { Equality of } \\
\text { Variances }\end{array}$} & \multicolumn{7}{|c|}{ t-test for Equality of Means } \\
\hline & \multirow[t]{2}{*}{$\mathrm{F}$} & \multirow[t]{2}{*}{ Sig. } & \multirow[t]{2}{*}{$\mathrm{t}$} & \multirow[t]{2}{*}{$\mathrm{df}$} & \multirow[t]{2}{*}{$\begin{array}{l}\text { Sig. (2- } \\
\text { tailed) }\end{array}$} & \multirow[t]{2}{*}{$\begin{array}{c}\text { Mean } \\
\text { Difference }\end{array}$} & \multirow[t]{2}{*}{$\begin{array}{l}\text { Std. Error } \\
\text { Difference }\end{array}$} & \multicolumn{2}{|c|}{$\begin{array}{l}95 \% \text { Confidence } \\
\text { Interval of the } \\
\text { Difference }\end{array}$} \\
\hline & & & & & & & & Lower & Upper \\
\hline $\begin{array}{l}\text { Positive } \\
\text { Feeling }\end{array}$ & 4.130 & .044 & 1.117 & 148 & .266 & -1.655 & 1.482 & -4.584 & 1.274 \\
\hline $\begin{array}{l}\text { Friendship } \\
\text { Satisfaction }\end{array}$ & .386 & .535 & 3.219 & 148 & .002 & -6.154 & 1.912 & -9.933 & -2.376 \\
\hline $\begin{array}{c}\text { Overall } \\
\text { Frienship }\end{array}$ & 1.630 & .204 & 2.358 & 148 & .020 & -7.809 & 3.312 & -14.354 & -1.265 \\
\hline
\end{tabular}

Table 4. Comparison of cross-ethnicity friendship quality by gender

\section{Same Ethnicity Friendship Mean}

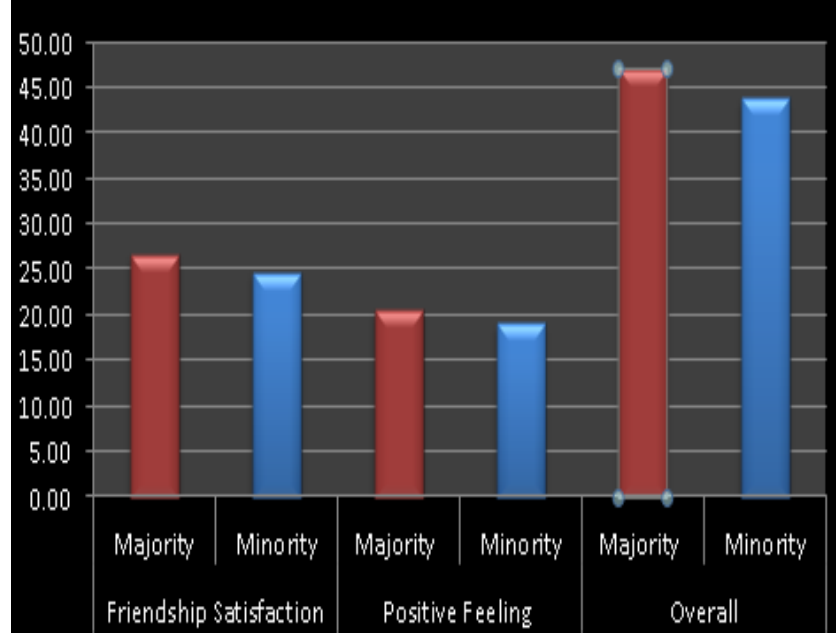

\begin{tabular}{|l|r|r|}
\hline \multicolumn{3}{|c|}{ Same Ethnicity Friendship } \\
\hline & Ethnicity & Mean \\
\hline Friendship Satisfaction & Majority & 26.61 \\
& Minority & 24.73 \\
\hline Positive Feeling & Majority & 20.57 \\
\hline Overall & Minority & 19.17 \\
& Majority & 47.18 \\
\hline
\end{tabular}




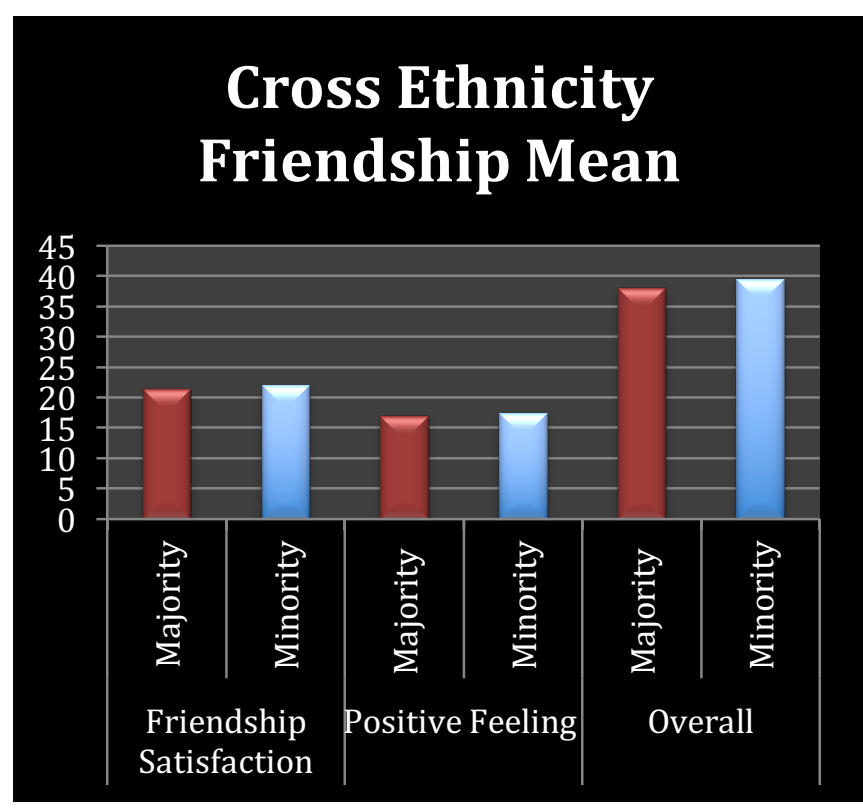

\begin{tabular}{|l|c|c|}
\hline \multicolumn{3}{|c|}{ Cross Ethnicity Friendship } \\
\hline & Ethnicity & Mean \\
\hline Friendship Satisfaction & Majority & 21.17 \\
& Minority & 21.87 \\
\hline Positive Feeling & Majority & 16.79 \\
& Minority & 17.44 \\
\hline Overall & Majority & 37.96 \\
& Minority & 39.31 \\
\hline
\end{tabular}

\section{Same Ethnicity Friendship Mean}

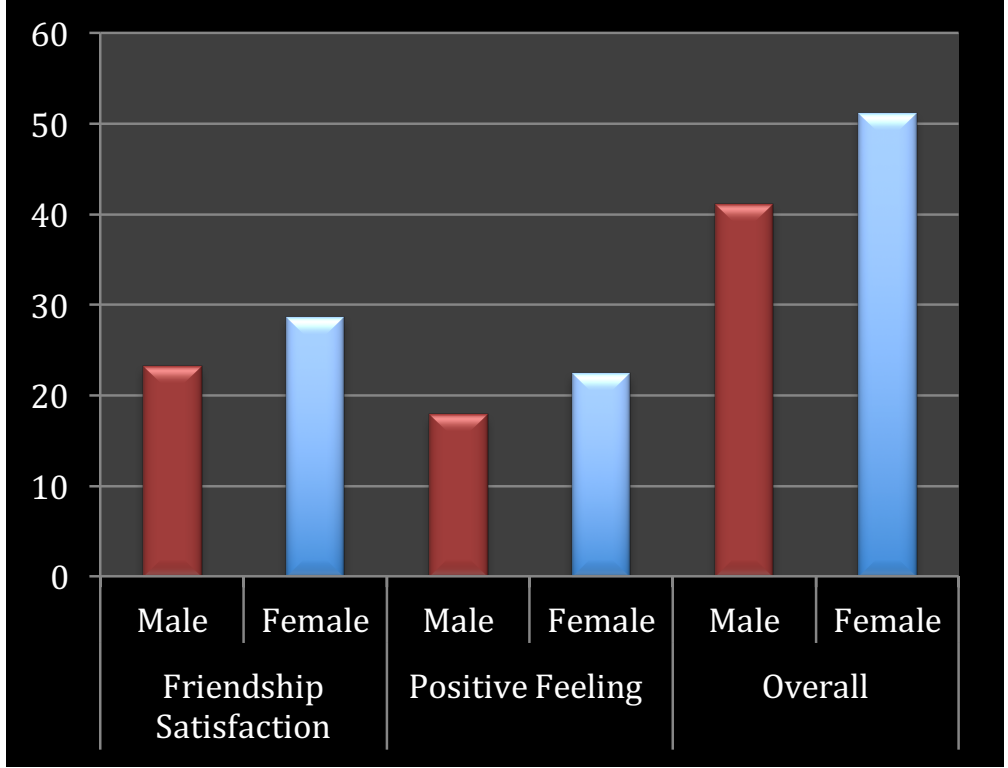

\begin{tabular}{|l|l|c|}
\hline \multicolumn{3}{|c|}{ Same Ethnicity Friendship } \\
\hline & Gender & Mean \\
\hline Friendship Satisfaction & Male & 23.25 \\
& Female & 28.67 \\
\hline Positive Feeling & Male & 17.84 \\
& Female & 22,39 \\
\hline Overall & Male & 41,09 \\
& Female & 51,06 \\
\hline
\end{tabular}




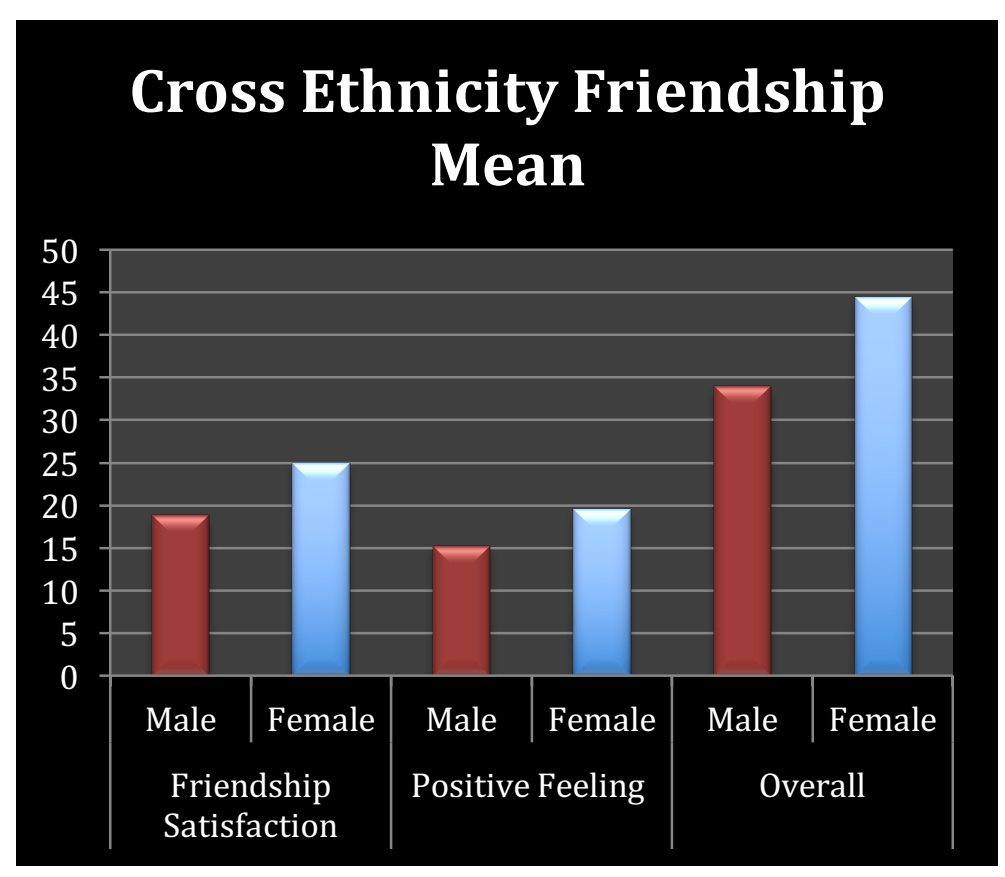

\begin{tabular}{|l|l|c|}
\hline \multicolumn{3}{|c|}{ Cross Ethnicity Friendship } \\
\hline & Gender & Mean \\
\hline \multirow{2}{*}{ Friendship Satisfaction } & Male & 18.77 \\
\hline Positive Feeling & Female & 24.93 \\
\hline \multirow{2}{*}{ Overall } & Male & 15.18 \\
& Female & 19.51 \\
\hline & Male & 33.95 \\
\hline
\end{tabular}

